since it is cooled to an extent dependent on the local particle velocity amplitude. In this way, velocities and absorption coefficients in a number of organic vapours are being measured. A modification of this technique, in which the wire is traversed in planes parallel to the face of the crystal but at different distances in front of it, serves to show to what extent at the lower ultrasonic frequencies diffraction from a forthright beam of plane waves occurs, and permits of correction to the attenuation as observed to be made in order to derive that proper to the vapour alone. This was demonstrated by Mr. K. Matta.

The remaining paper, by Dr. E. A. Alexander, of H.M. Underwater Detection Establishment, dealt with a different aspect of the propagation of ultrasonics in liquids, that is, the formation of cavities. When a sound wave passes through water, the water is alternately subjected to positive and negative pressures in the respective half-periods of the wave. As the intensity is increased and the point is reached where the negative pressure equals the external pressure acting on the water plus its cohesive force, the water breaks into a cavity, consisting of water vapour together with air which comes out of solution. As the pressure starts to increase again the cavity collapses rapidly with the production of the characteristic noise which accompanies all cavitation.

Owing to the difference in acoustic impedance between air (or a vacuum) and water or solid materials, this onset of cavitation limits the efficiency of a high-power ultrasonic transducer as an under. water signal source. The object of these experiments is to investigate this limitation in terms of hydrostatic pressure, air content and signal duration. The transducer is mounted in a tank of water with a hydrophone at a certain distance to pick up the signal. In the absence of cavitation, the signal sent out, that is, the potential applied to the transducer, is of the same form, as seen on a cathode-ray oscillograph, as that picked up by the hydrophone. When the power applied is increased to the point at which cavitation sets in, bubbles are seen in the water, the signal is distorted and an audible noise, apparently due to the collapse of the bubbles, is produced. The cavities often form at a nucleus near the transducer surface, with a 'meteor tail' spreading away from the 'head'. These may persist for the duration of the signal.

Some interesting demonstrations of ultrasonic cavitation induced in flasks of water and a high-speed ciné-film of bubble formation were shown by Mr. R. Hall.

F. G. RICHARDSON

\section{THE COAL INDUSTRY IN GREAT BRITAIN}

A JOINT session of Sections B (Chemistry), C (Geology) and A (Economics and Statistics) of the British Association was held at Newcastle upon Tyne on Septerab 55 to discuss the present position of the coal infustry in Great Britain. Prof. A. Beacham of Cardiff ppeted the discussion on behalf of the Sertidn of Edonomics, and Mr. I. G. C. Dryden (Britsispofol Utilisation Research Association) and Prof. H. G. A. Hickling of Newcastle followed on behalf of the Sections of Chemistry and Geology, respectively. The proceedings closed with a contribution from Mr. W. Maclean (deputy labour director, Northern Division, National Coal Board), who took the place of Mr. Sam Watson of the National Union of Mineworkers.

Prof. Beacham argued that the task of the Coal Board has been made difficult, if not impossible, by reason of the vagueness and inconsistency of the Act by which it was constituted and by its subjection to political control. The effect of this is to be seen most clearly in the approach of the Board to its long-term technical reorganisation programme. The Board seems to be unable to make up its mind whether the 'national plan' should be dominated by efficiency factors or social factors. The Coal Mines Nationalization Act laid considerable stress on both, and in any event the last word on capital reorganisation schemes lies with the Minister of Fuel. Prof. Beacham then referred to the disappointment of expectations that nationalization would inaugurate a new era in indus. trial relations in the industry. The reasons for this are deep-seated, but two points have been generally overlooked. First, the men, with long and bitter experience of over-production behind them, are unlikely to respond to the call for increased productivity on the facts as presented to them; and secondly, the antiquated, anomalous and almost unintelligible wages structure of the industry is a prolific cause of friction between management and men.

On price policy, Prof. Beacham emphasized the fundamental importance of proper grading of coals, and suggested that economists, chemists and geologists would need to put their heads together before these problems could be solved. In conclusion, he entered a plea for lower output targets in the next few years. High output targets are responsible for keeping costs and prices high, and signs are not lacking that Great Britain may have difficulty in disposing of her export surplus before the long-term technical reorganisation programme has produced any marked effect.

Mr. Dryden agreed with the general tenor of the preceding remarks and underlined the possibility of high costs and prices, together with competition, permanently restricting the demand for coal. As a measure of insurance against this, and (taking a shorter-term view) as a means of introducing flexibil. ity and possibly reducing the price of fuel while maintaining or increasing the gross revenue from a ton of coal, he suggested that a greater proportion of scientific research in the coal industry should be directed towards the establishment of new chemical industries based on direct production (that is, using coal, not carbonization products) from low-grade coal residues, at present discarded. Such industries could also process a small proportion of the salable output in times of reduced demand. Mr. Dryden emphasized that coal is a complex organic substance of largely unknown constitution. A knowledge of its constitution would greatly accelerate progress, yet very little is being done. Advantage should be taken of this complex chemical nature by endeavouring to produce under mild and controlled conditions sub. stances which are expensive to synthesize from petroleum. The biggest potential market probably lies in the field of constructional materials. Export of high-priced coal products in preference to raw coal should be encouraged when conditions allow ; preparation should be made for sacrificing part of the fuel load to other sources of power in order to conserve our relatively meagre resources-compensation for this being sought in alternative markets for the new chemical products. Mr. Dryden advocated a flexible 
balance of activity bretween coal produotion and chemical processing of coal in order to maintain an appropriate balance between demand and supply. Pointing out that such measures could not in themselves solve the problems of the industry, he estimated, nevertheless, that a very valuable contribution is possible.

The vital importance of a thorough investigation of the actual resources in Britain of the various types of coal was emphasized by Prof. Hickling. In the 'rapid survey' recently made by the Fuel Research Department, these were classified into nine main groups, based on their volatile yields and coking properties. The broad result of the survey was to show that, while the reserves of nearly all types are likely to last for another century, and some for substantially longer, the outlook is very different when the various coalfields are considered individually. In the North-Easterm coalfield the best metal. lurgical coking coals, practically confined to this field, are likely to be exhausted within fifty years. The coals in this and other fields show systematic area variation in composition, so that as different areas are exhausted the general character of the coal produced must change progressively. The valuable anthracites and low-volatile steam-coals, of which our known resources are practically confined to a portion of the South Wales field, are likely to be exhausted before other types from that field.

Prof. Hickling specially stressed the fact that while the proved coal resources of Great Britain give no ground for concern as to the immediate future, we cannot justify their continued exploitation without the fullest assessment of their extent and the probable duration of various types in different areas. The relatively large area of exposed and long-known coalfields, along with other circumstances, has long delayed attempts to locate possible buried coalfields which may yet be found. Modern methods of geophysical survey, elaborated in the search for oil, can now be applied to localize this problem and to prepare the way for final investigation by boring. This is a project of urgent importance.

Every coal is a complex mixture of substances of widely differing properties. Some of these may be separated with relative ease, others only with greater difficulty There is a wide field for investigation of the economic possibilities of the preparation of coals on such lines, either for their use as special fuels or as raw materials. Blending of coals or of their separated components also demands development. In Great Britain little attention has been paid to the fact that at any point the deeper coals are in general of higher carbon content than those above. As mining is necessarily being driven deeper, this in turn must have an influence on the average quality of future products.

The final speaker, Mr. Maclean, refused to take a pessimistic view of the future of the industry, and declared that he is satisfied that within the next decade the National Coal Board will be producing about 250 million tons of coal per annum. Costs could be cut by reorganising transport arrangements so that a higher proportion of the available manpower may be concentrated at the face. He then referred to the very high average age of the present labour force in the mines, and stressed the need for stimulating juvenile recruitment. In this connexion, the Board has adopted a plan which should make mining a more attractive occupation to young entrants. In future, when a boy enters the industry, an assessment of his potentialities will be made at the end of his statutory training. If suitable, he will pass on at the age of sixteen to receive a course of general instruction in mining, and at eighteen will specialize in mechanics, electricity, surveying and mine management. Beyond this stage, scholarships will be available to take the best men on to the university. Mr. Maclean is satisfied that as these plans bear fruit the industry will prosper, and the country will not regret the decision to organise it on national lines.

A. BEACHAM

\section{OBITUARIES}

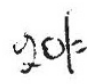

\section{Prof. Major Greenwood, F.R.S.}

MAJOR GREENW 6 , professor emeritus of epidemiology and kital statistics in the University of London, died on Octoper 5 as he was about to take the chair at a meeting of the Cancer Research Committee. $\mathrm{He}$ was sidtynine. His father, Dr. Major Greenwood, wa general practitioner in north-east London, a nal of many parts interested in the humanities. From him Greenwood inherited literary tastes and a love of the countryside, particularly Epping Forest, where he lived for more than forty years, at Loughton. $\mathrm{He}$ used to recall with pleasure long cycle rides taken as a boy with his father in Essex and a holiday in Skye. I had known him for forty-five years at work and at leisure.

Greenwood was educated at the Merchant Taylors' School, of which he always spoke with affection, on the classical side, and there obtained a sound training in mathematics, to be extended later by private reading in the midst of many other activities. Nor did he let the classics slide. In later life he read early Latin texts of medical writers unaided, though he relied on his friend and colleague, Dr. May Smith, when reading obscure and un-Attic Greek texts.

From school he entered the London Hospital Medical College, qualified M.R.C.S., L.R.C.P. in 1904, and remained there as demonstrator in physiology, under Prof Leonard Hill, until 1910. His first book, "The Physiology of the Special Senses", was pub. lished in that year. During those years he also studied with Prof. Karl Pearson at the Biometrical Laboratory at University College, and learnt the then new technique of mathematical statistics applied to natural selection in man, a technique he was to employ later with brilliant results in his own chosen fields of vital statistics and epidemiology. In 1910 Greenwood was appointed statistician to the Lister Institute, and remained attached to the Institute until he was asked to take charge of medical statistics at the newly created Ministry of Health in 1919; but for the last two years of the First World War he was seconded to take charge of the medical research section of the Ministry of Munitions. His work during that period on the frequencies of repeated accidents among munition workers, done in collaboration with G. Udny Yule, was based on an application of a generalized Poisson series; it became a classic and inspired fundamental work later by his colleagues, Newbold and Soper, at the School of Hygiene, and applications by the staff of the Industrial Health Research Board.

Greenwood left the Ministry of Health in 1928 to become the first professor of epidemiology at the London School of Hygiene and Tropical Medicine, a 